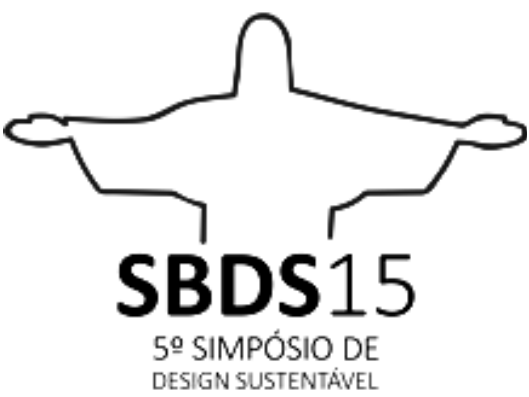

Rio de Janeiro, 11 de novembro a 13 de novembro de 2015

\title{
SAVE THE BIO: O DESIGN COMO FERRAMENTA CONTRA A PERDA DA BIODIVERSIDADE
}

\author{
Liana Domeneghini Chiaradia \\ UFSC \\ lihh.chiaradia@gmail.com \\ Ana Veronica Pazmino \\ UFSC \\ ana.veronica@ufsc.br
}

\begin{abstract}
Resumo: A sociedade atual vive em um sistema linear em crise, baseado no consumo. Isto causa uma série de problemas ambientais e sociais, entre eles a perda da biodiversidade, que compromete toda a vida no planeta Terra. Neste artigo são abordados dados que comprovam a gravidade deste fato e alternativas para reduzi-lo, por meio do Design. São realizadas análises de cases de Design Gráfico e de Design de Interação, e uma proposta de uma nova ferramenta: o aplicativo Save the Bio.
\end{abstract}

Palavras-chave: biodiversidade, design, interação, mobile.

Abstract: The current society lives in a linear system in crisis, based on consumerism. Its causes a lot of environmental and social problems, and one of them is the loss of biodiversity, that affects all the life on Earth. In this article are discussed details that prove the seriousness of this fact and alternatives to reduce it, through Design. Graphic Design and Interaction Design cases are analyzed, and a new tool is proposed: Save the Bio app.

Keywords: biodiversity, design, interaction, mobile

\section{INTRODUÇÃO}

A sociedade contemporânea vive em um sistema linear em crise, baseado em uma economia consumista. Leonard (2007) comenta que este tipo de economia começou de fato nos anos 50 nos Estados Unidos, depois da Segunda Guerra Mundial, como forma de ascender a economia. Nesta época, Lebow (1955), articulou uma solução que se tornou a base do sistema econômico de muitos países:

Nossa economia altamente produtiva exige que façamos do consumo o nosso meio de vida, que devemos converter a compra e uso desses bens em rituais, que busquemos nossa satisfação espiritual e a satisfação do nosso ego, em consumo. Precisamos ter coisas 
consumidas, queimadas, substituídas e descartadas de modo mais e mais acelerado. (LEBOW, 1955, p.3)

Leonard (2007) afirma que esta estratégia econômica consumista trouxe uma série de problemas ao planeta, tanto ambientais como sociais. A autora aponta como principais consequências a dominação de países subdesenvolvidos, extração de matérias-primas de forma indevida, destruição da natureza e de culturas milenares, poluição, consumo insaciável, descarte de lixo indevido, produção de substâncias altamente tóxicas, descomprometimento do governo com a sociedade, exportação de lixo, obsolescência percebida e programada e acúmulo de bens.

Em meio a todos estes problemas, um dos grandes desafios a ser revertido é a perda da biodiversidade. Segundo a WWF Brasil (2015d), o comportamento da sociedade humana alterou os ecossistemas da Terra com maior rapidez e amplitude nos últimos 50 anos do que em qualquer outro período da história humana. Porém, a conservação das espécies e ecossistemas que as abrigam é diretamente ligada ao futuro da humanidade.

A WWF Brasil (2015d) afirma que a perda da biodiversidade é a maior ameaça à estabilidade e à segurança do mundo hoje e que as ações dos próximos anos serão determinantes. Diversas pesquisas e levantamentos estão sendo feitos, ONGs e programas federais criados e pessoas e empresas mobilizandose em prol da causa. A perda da biodiversidade tornou-se um problema multidisciplinar e mundial.

Neste artigo será feita uma breve análise sobre as causas da perda da biodiversidade, bem como, levantamentos de dados que comprovam como ela se tornou uma crise mundial que necessita de soluções imediatas. O Design - com ênfase no design gráfico e no design de interação - é apresentado como alternativa para o combate da perda da biodiversidade, com análise de cases e a proposta de um novo: o aplicativo Save the Bio.

\section{O DESIGN COMO SOLUÇÃO}

A palavra "biodiversidade" foi criada em 1985, como uma contração de "diversidade biológica" (WWF BRASIL, 2015c). Para Wilson (1997) biodiversidade pode ser definida como "a totalidade da variação hereditária em formas de vida, em todos os níveis de organização biológica". Já, o decreto n. 2.519 de 1998, que promulgou a Convenção sobre Diversidade Biológica (CDB) no Brasil, e o artigo 2.ㅇ, III, da Lei n. ${ }^{\circ} 9.985$ de 2000 , diz que biodiversidade é a variabilidade de organismos vivos, compreendendo os ecossistemas e os complexos ecológicos de que fazem parte, bem como, a diversidade dentro de espécies e de ecossistemas (MINISTÉRIO DO MEIO AMBIENTE, 2000).

Segundo a WWF Brasil (2015d), a biodiversidade sofreu redução de mais de um quarto nos últimos 35 anos. Em menos de 40 anos o mundo perdeu $30 \%$ de sua biodiversidade original. Nas regiões tropicais, a queda foi de $60 \%$ da fauna e flora original, com $70 \%$ de queda de espécies aquáticas.

Antes, a extinção estava ligada aos desastres naturais, como erupções vulcânicas ou quedas de asteroides. Hoje, o homem é apontado como principal vetor da extinção. Nos últimos cinco séculos, 80 das 5,57 mil espécies de mamíferos desapareceram. Desde a década de 70, as populações dos vertebrados não domésticos sofreram uma queda de 30\%. (ESTADÃO, 2014)

Um estudo da Universidade de Stanford, na Califórnia, afirma que apenas uma em cada 10 milhões de espécies desaparecia no período de um ano. O número aumentou mil vezes: 100 em cada milhão são eliminadas por ano (Estadão, 2014).

Nunes e Spitzcovsky (2010) apontam que se toda a população mundial vivesse de acordo com os padrões de vida de países industrializados, seriam necessários mais de 4 planetas para suprir as necessidades de recursos naturais. Vivemos em um descompasso ecológico, ou seja, retiramos recursos da natureza em velocidade superior à sua capacidade de regeneração e criamos resíduos maiores que a sua capacidade de absorção. (WWF BRASIL, 2015d). 
Este descompasso ecológico também gera sérias mudanças climáticas, que possuem efeitos e impactos desconhecidos sobre a biodiversidade. Pesquisadores comentam que "a capacidade (ou incapacidade) de os seres vivos se adaptarem a esses impactos é uma grande incógnita" (WWF BRASIL, 2015d).

O Brasil é o país com maior diversidade biológica, abrigando entre $15 \%$ e $20 \%$ de número total de espécies do planeta, porém, nos próximos anos, podem desaparecer mais de mil espécies (ESTADÃO, 2014). A onça pintada, maior carnívoro do país, foi afetada com a redução da mata atlântica e caças e hoje existem apenas $250 \mathrm{em}$ todo o território. Só na Amazônia, são derrubadas 2.000 árvores por minuto e, atualmente, existem apenas $10 \%$ da sua cobertura original (LEONARD, 2007).

Outro grande desafio para conservar as espécies é a sua catalogação: são conhecidas aproximadamente 1,9 milhão de espécies no mundo, mas, estima-se que existam 10 milhões no total. Deste modo, não é possível saber informações sobre o habitat dessas espécies desconhecidas e suas taxas de extinção, dificultando a sua conservação (SANTOS, 2014).

Segundo a IUCN (União Mundial para a Natureza), o valor monetário dos bens e serviços prestados pelos ecossistemas é estimado na ordem de US\$ 33 trilhões ao ano (WWF BRASIL, 2015b) e a extinção de espécies gera também prejuízos econômicos. Um exemplo é a redução de $40 \%$ do número de abelhas, que causou um prejuízo de U\$ 2 bilhões nos últimos seis anos. (ESTADÃO, 2014). Além da produção do mel, as abelhas também são uma das responsáveis pela polinização de culturas agrícolas mundiais e, consequentemente, da segurança alimentar.

Porém, não é apenas uma questão econômica: estima-se que colhemos entre 50.000 e 70.000 espécies vegetais para uso na medicina tradicional e moderna; cerca de 100 milhões de toneladas de criaturas aquáticas são retiradas da natureza todos os anos para a alimentação; a carne de animais silvestres é fonte de alimento e meios de subsistência dos humanos, principalmente em lugares com índices de pobreza e insegurança alimentar. A diversidade biológica "'é o elo entre todos os organismos existentes na terra, que liga cada um deles a um ecossistema interdependente, em que cada espécie desempenha sua função" (WWF BRASIL, 2015b).

Embora exista um grande progresso no desenvolvimento de áreas de proteção, os números não são ecologicamente representativos e não estão melhorando a proteção da biodiversidade (SANTOS, 2014). É necessário implantar medidas eficazes, que auxiliem na diminuição do uso da fauna e flora para suprir as necessidades humanas, como a implantação de políticas de proteção em áreas importantes para a preservação da biodiversidade, a melhora nos mecanismos de monitoramento de extração de matérias e a mudança dos hábitos de consumo (NUNES; SPITZCOVSKY, 2010). Pesquisadores afirmam que é essencial o investimento em tecnologias que possibilitem a coleta de dados e de mapas e a troca de informações entre países (ESTADÃO, 2014).

Outra ferramenta na causa contra a perda da biodiversidade é o uso do Design. Segundo a ADG Brasil (2009), os problemas gerados em uma sociedade e presentes na vida das pessoas estão suscetíveis a serem resolvidos através do Design.

Design significa ter e desenvolver um plano, um projeto, significa designar. É trabalhar com a intenção, com o cenário futuro, executando a concepção e o planejamento daquilo que virá a existir. Criar, desenvolver, implantar um projeto - o design - significa pesquisar e trabalhar com referências culturais e estéticas, com o conceito da proposta. É lidar com a forma, com o feitio, com a configuração, a elaboração, o desenvolvimento e o acompanhamento do projeto. (MOURA, 2003, p.118)

Para Schneider (2010), Design é uma forma de "visualização criativa e sistemática dos processos de interação e das mensagens de diferentes atores sociais" e das "diferentes funções de objetos de uso e sua adequação às necessidades dos usuários ou aos efeitos sobre os receptores". Atuando em áreas multidisciplinares, observaremos exemplos do uso do Design em prol da biodiversidade.

\subsection{O Design Gráfico como ferramenta}

Uma série de anúncios e campanhas relacionados à biodiversidade tem sido desenvolvidas, criando destaque mundial. Com o uso do Design Gráfico como ferramenta visual, as campanhas pregam a conscientização e mudança de hábitos da população (HYPENESS, 2014a). 
Um exemplo são as peças gráficas da WWF. Surgida em 1961, a WWF (Fundo Mundial para a Natureza), é uma Organização Não Governamental (ONG) internacional que atua nas áreas de conservação, investigação e recuperação ambiental. Com uma série de investimentos e projetos, uma das formas de expor sua missão é através de campanhas visualmente impactantes. A Figura 1 mostra que um animal não pode ser reparado em uma oficina.

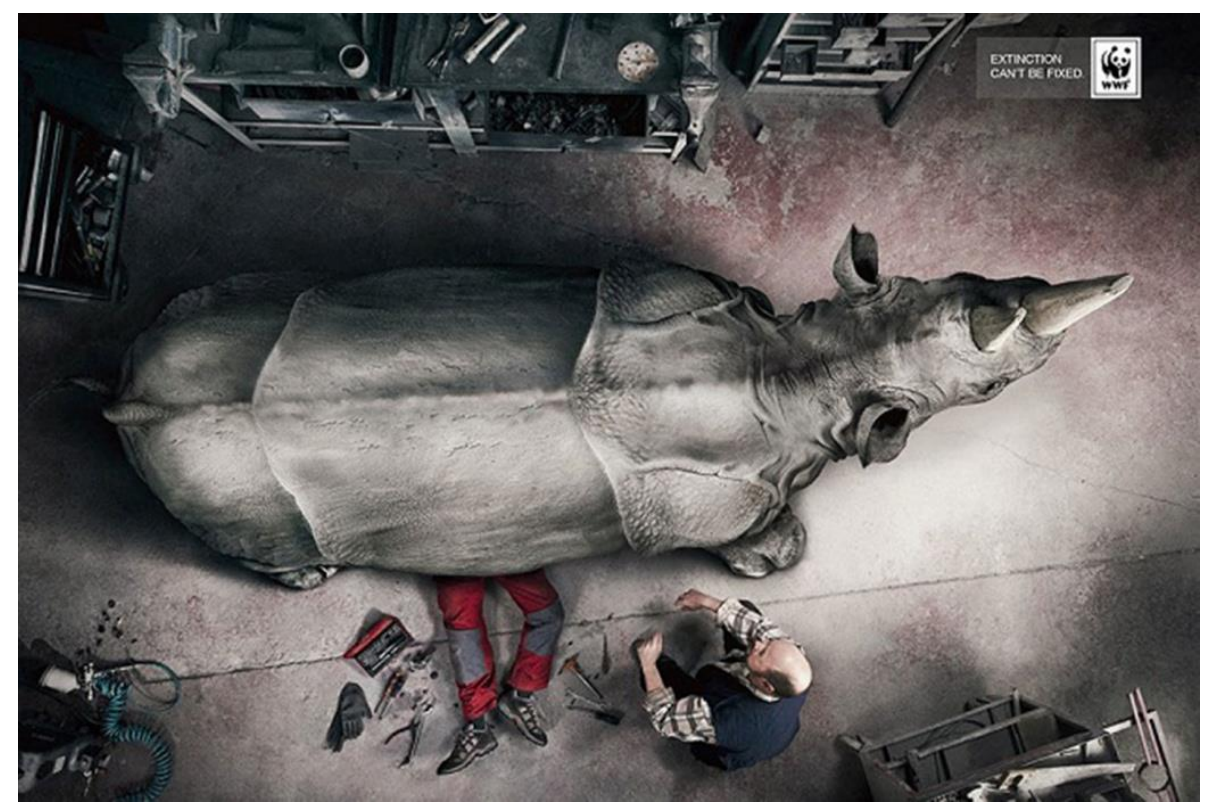

Figura 1 - Campanha "A extinção não pode ser resolvida", da WWF.

Fonte: Hypeness (2014a).

O uso de composições surreais, porém, com estilo realista, faz com que o receptor leve o anúncio para sua realidade. Situações desconfortáveis são criadas, com adição de frases diretas ou perguntas reflexivas, agregando um forte apelo visual e emocional no receptor, que é convidado a refletir sobre questões alarmantes e paradigmas pessoais e sociais.

Outro exemplo do uso do Design Gráfico ferramenta é o da campanha Stop Shark Finning, que usou o recurso da infografia para expor sua luta contra o finning - prática onde as barbatanas dos tubarões são cortadas e seus corpos jogados, ainda vivos, no mar.

O termo infográfico vem do inglês informational graphics e o seu uso revolucionou o layout das páginas de jornais, revistas e sites. É uma forma de representar informações técnicas como números, mecanismos e/ou estatísticas, que devem ser sobretudo atrativos e transmitidos ao leitor em pouco tempo e espaço. (CAIXETA, 2005, p.1)

Milhões de tubarões morrem todos os anos por causa do finning, pois as barbatanas são consideradas iguarias culinárias, principalmente na China e Hong Kong (HYPENESS, 2014b). O abate clandestino dos tubarões alcançou um ritmo insustentável: desde os anos 1970, as populações de várias espécies têm sido dizimadas em mais de 95\%, com risco de extinção (STOPSHARKFINNING.NET, 2013).

Usando recursos informacionais e visuais, o infográfico usa o apelo emocional para divulgar a campanha, que visa uma proibição mundial do finning. Uma grande parcela da população possui medo de tubarões por serem animais agressivos, dessa forma, no infográfico é feita uma comparação entre a quantidade de pessoas mortas por ano por tubarões e a quantidade de tubarões mortos por hora pelos humanos (HYPENESS, 2014b). As figuras 2 e 3 mostram um infográfico. 


\section{SHARK ATTACK \\ SHARKS KILL THIS MANY PEOPLE PER YEAR \\ MAmikhillt \\ PEOPLE KILL THIS MANY SHARKS PER HOUR}

Figura 2 - Início do infográfico Shark Attack

Fonte: Hypeness (2014b).

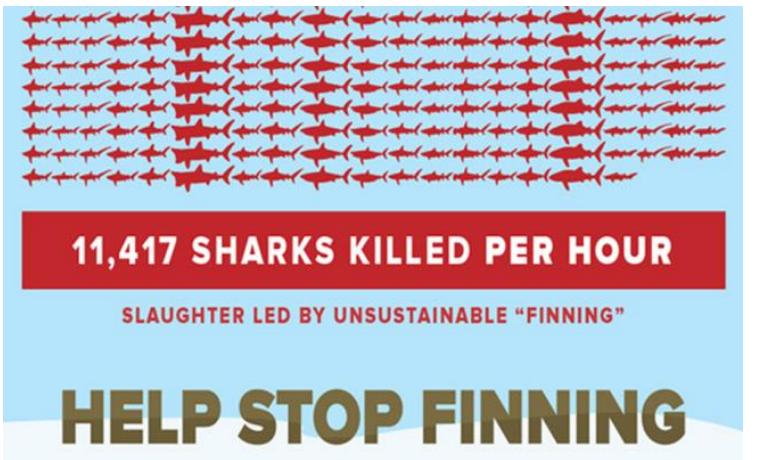

Figura 3 - Parte final do infográfico Shark Attack

Fonte: Hypeness (2014b).

O infográfico mostra a grande quantidade de tubarões mortos por hora de forma totalmente visual com o uso de ícones de diversas espécies de tubarões, causando grande impacto visual. Faz uso das cores azul para o fundo - que representa a água - e vermelha para os tubarões - que expressa o sangue e agressividade da prática de finning. Desta forma, a mensagem chega ao leitor de forma impactante, comovedora e sensibilizadora, atingindo seu objetivo.

\subsection{0 uso do design de interação como ferramenta}

Design de interação significa projetar produtos interativos que apoiem a maneira como as pessoas se comunicam, trabalham e interagem em seus cotidianos, de modo a criar experiências ao usuário, segundo Rogers et al. (2013).

O Sistema de Informação em Saúde Silvestre (SISS-Geo) desenvolvido pela Fiocruz (Fundação Oswaldo (ruz) é um exemplo de aplicativo em prol da biodiversidade. Ele auxilia no monitoramento da saúde silvestre e pública, com o mapeamento colaborativo de ocorrências anormais de animais, que possam representar desequilíbrios gerados por atividades humanas sobre os ecossistemas. 

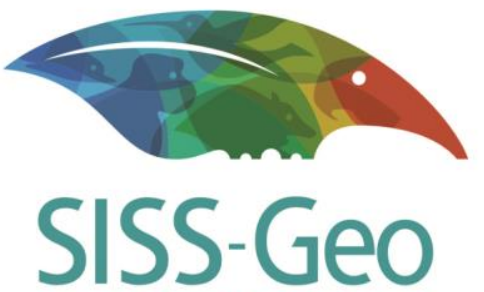

Sistema de Informação em Saúde Silvestre

TOQUE PARA INICIAR ...

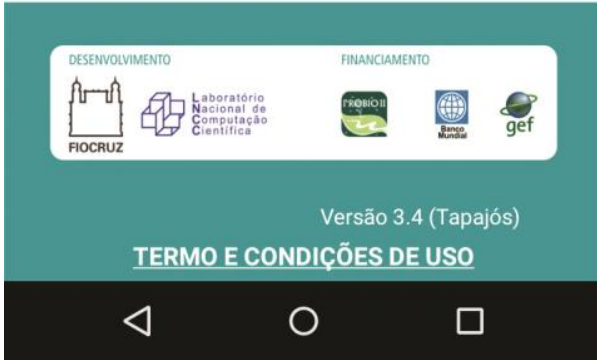

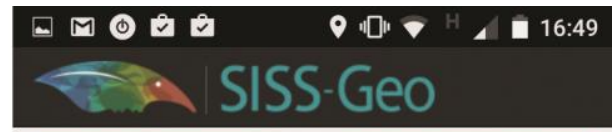
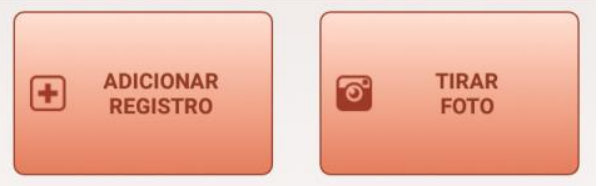

\section{$>$ Registros}

> Mapa

$>$ Cadastro

$>$ Colabore conosco

Figura 4 - Telas do aplicativo SISS-Geo. Fonte: IDG Now! (2014).

A partir dos registros dos usuários de animais observados e da informação de possíveis anormalidades e das características do ambiente onde foi feita a observação, o sistema gera modelos de alerta de ocorrências, que poderão ser analisadas e resolvidas ou minimizadas com maior rapidez (IDG NOW!, 2015).

Outro exemplo de aplicativo é o Map of Life (MOL), desenvolvido na Universidade de Yale, nos Estados Unidos. A partir da localização do usuário, são disponibilizadas informações sobre quais animais e plantas estão próximos, integrando diversas fontes de dados de distribuição das espécies pelo mundo.
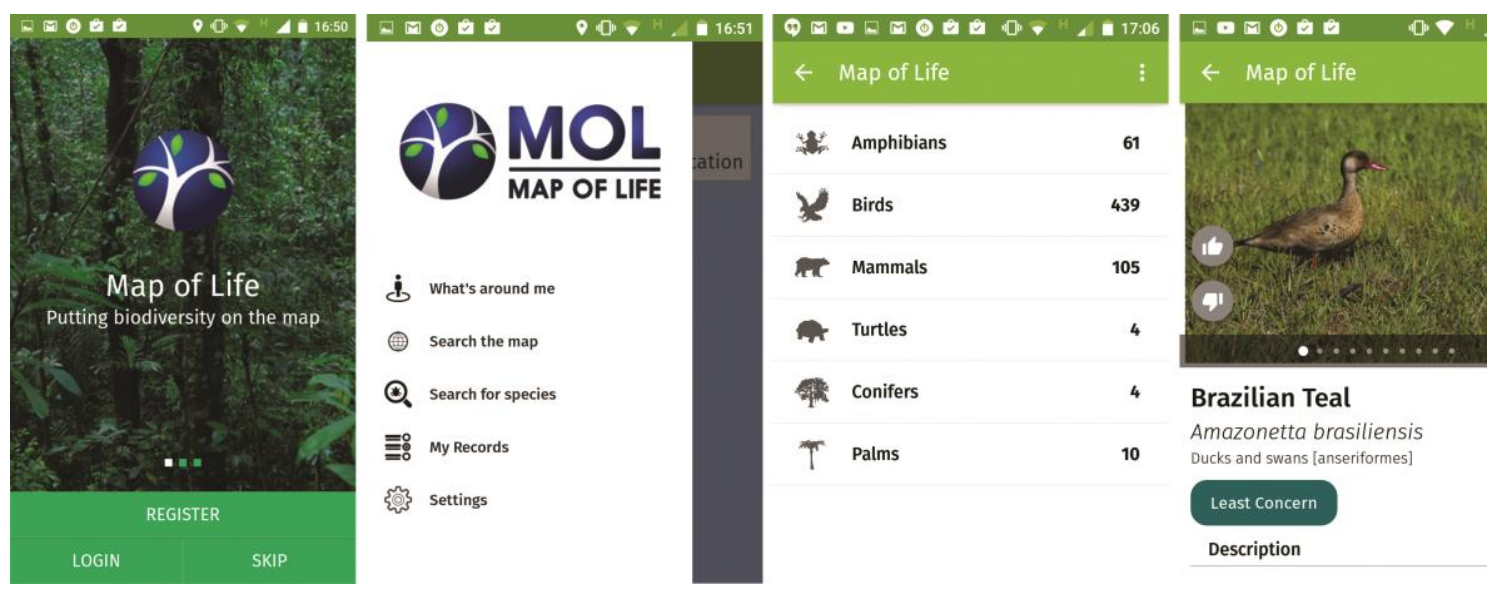

Figura 5 - Telas do aplicativo MOL. Fonte: Paschoal (2015). 
O aplicativo disponibiliza fotos que ajudam a identificar animais e plantas, juntamente com textos informativos. O usuário também pode criar listas pessoais de observação ou enviar informações, contribuindo com pesquisas científicas e projetos de conservação. Todos os dados são gerenciados, checados, armazenados e podem ser acessados via cloud hosting (PASCHOAL, 2015).

\subsection{Uma nova ferramenta: aplicativo Save the Bio}

Com base nas análises realizadas sobre os desafios contra a perda da biodiversidade, bem como, as pesquisas feitas sobre cases de Design em prol desta causa, uma nova ferramenta que une design gráfico ao design social e de interação é proposta.

A pesquisa teve como solução final o aplicativo "Save the Bio", que traz uma nova forma de educação ambiental. Ele visa disponibilizar informações a cerca da biodiversidade para os usuários, de modo a sensibilizá-los dos problemas existentes, bem como, maneiras de colaborar com a causa.

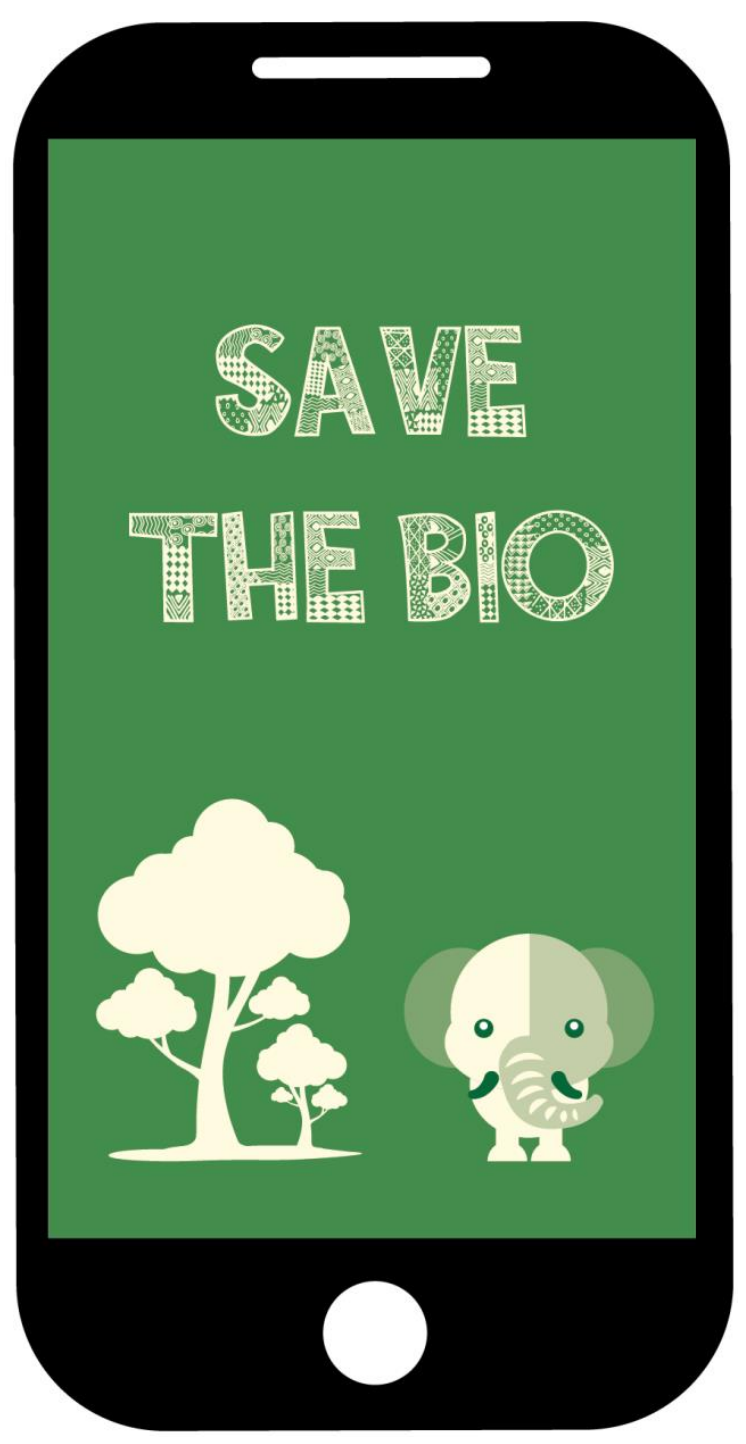

Figura 6 - Tela de splash do protótipo do aplicativo Save the Bio. Fonte: Elaborado pelo autor, com base na pesquisa realizada. 

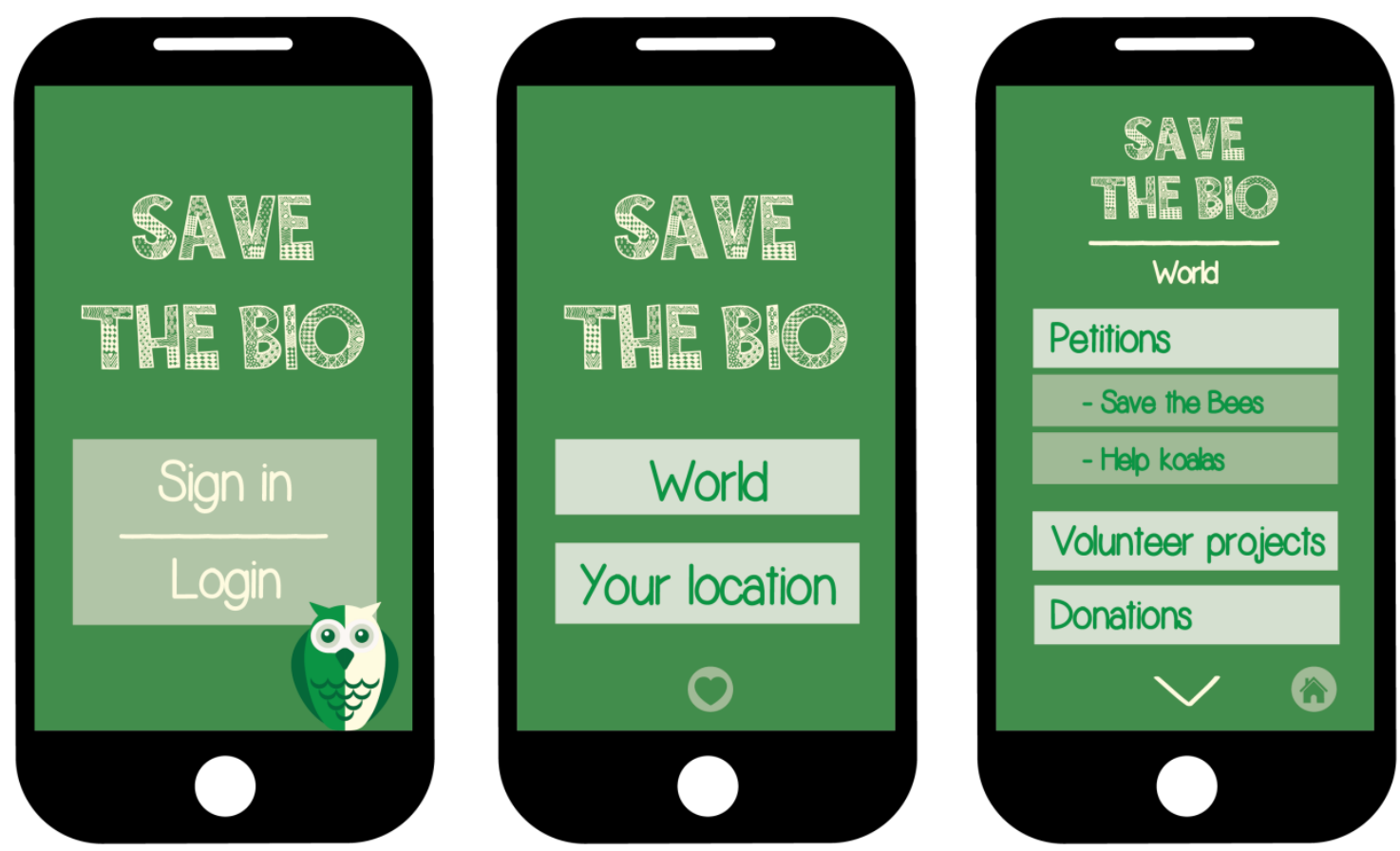

Figura 7 - Telas do protótipo do aplicativo: cadastro e login, menu e opção “Mundo”. Fonte: Elaborado pelo autor, com base na pesquisa realizada.

Ao abrir o aplicativo, o usuário deve se cadastrar ou fazer login e, após isto, um menu com duas opções de navegação são propostas. Na primeira, intitulada "World" (Mundo), são apresentadas petições em prol da biodiversidade (as quais o usuário pode assinar) e projetos voluntários de diversos países (nos quais o usuário pode participar de maneira online). O usuário também poderá fazer doações para os projetos e instituições.

Na segunda opção, "Your location" (Sua localização), através da ativação do GPS do dispositivo do usuário, o aplicativo encontra sua localização. Dessa maneira, ele disponibiliza informações referentes ao tipo de ecossistemas existentes no local onde o usuário se encontra; quais são os animais e vegetações em risco de extinção (e as principais causas); e os eventos e projetos existentes, nos quais o usuário pode se inscrever e participar. 

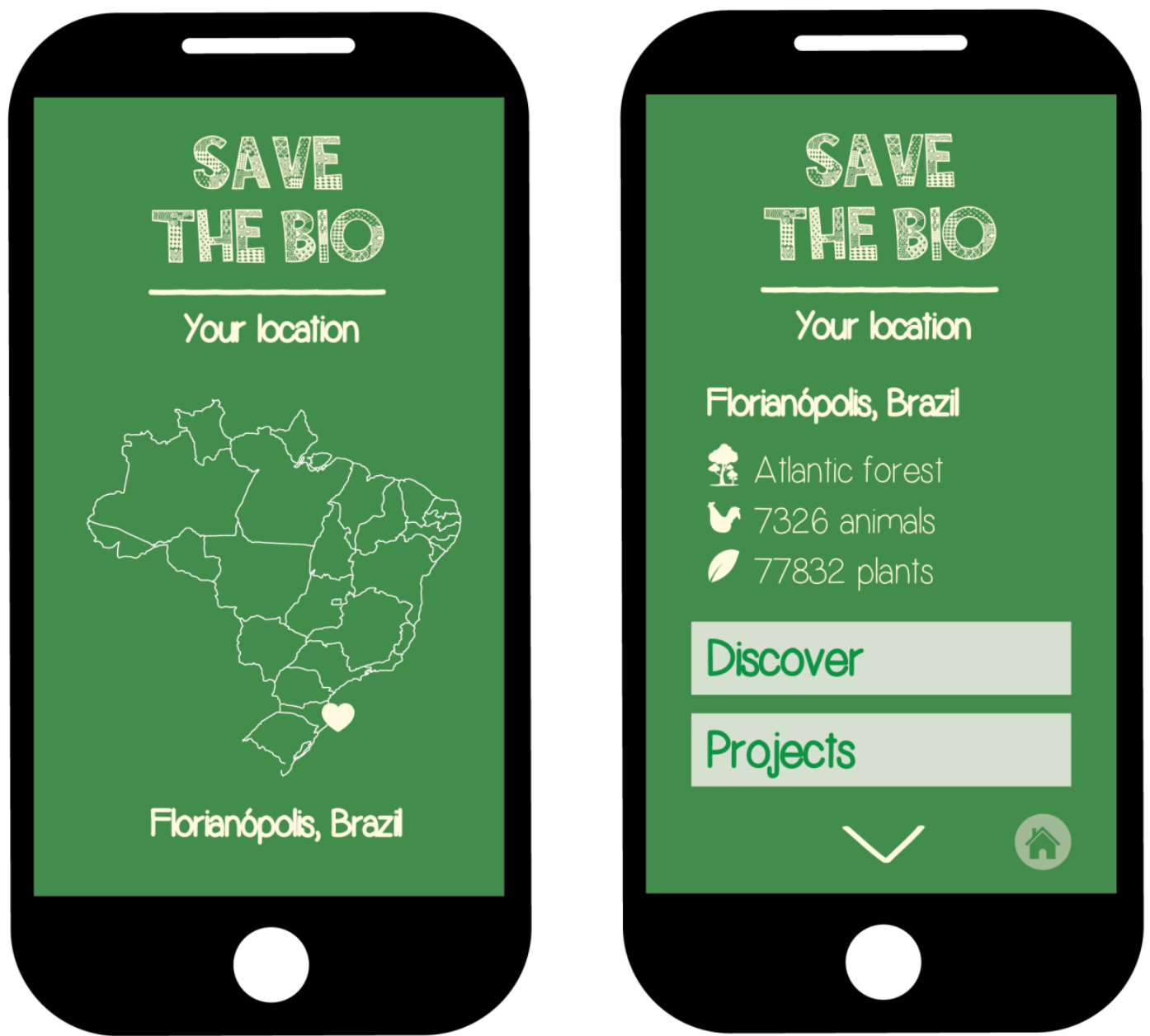

Figura 8 - Telas do protótipo do aplicativo: opção "Sua localização".

Fonte: Elaborado pelo autor, com base na pesquisa realizada.

Novos projetos ou informações podem ser cadastrados pelo usuário, os quais deverão passar por um processo de avaliação dos gestores do aplicativo. A interação também acontece pela possibilidade de compartilhamento das informações e ações do usuário por meio de redes sociais, como Facebook ou Twitter.

A escolha da solução como aplicativo foi feita por ele ser um dos recursos mais utilizados por usuários de smartphones e tablets - sendo que estes dois últimos, também são amplamente populares e já superam o uso de computadores para acesso à internet. Sete de cada oito minutos gastos consumindo mídia mobile ocorre por meio de aplicativos, sendo que $57 \%$ dos usuários de smartphones utiliza ao menos um aplicativo todos os dias (CANALTECH, 2014). O período atual encontra-se em um grande momento de desenvolvimento tecnológico unido ao cultural, e a internet e as redes sociais possuem função essencial na criação e no compartilhamento de ideias, projetos, serviços e produtos, que são levados dos meios online para os offline ou vice-versa (BOSTMAN; ROGERS, 2011).

A proposta tem como público-alvo, jovens entre 18 a 30 anos, também chamados de "millennials" ou "geração $Y$ ", pois estes cresceram em meio à expansão da internet e possuem grande familiaridade com dispositivos móveis, sendo os maiores usuários (WALTRICK, 2014). Segundo Bostman e Rogers (2011), os millennials reconhecem os custos implícitos no hiperconsumismo e são os principais agentes de mudança deste problema, com base na colaboração.

\section{CONCLUSÃO}

Por meio da análise realizada, é possível concluir que a perda da biodiversidade alcançou grandes proporções devido às ações humanas. Pesquisadores acreditam que ainda é possível reverter este quadro, mas são necessárias diversas mudanças. 
Os seres humanos precisam tornar-se mais conscientes de suas ações com o meio-ambiente, de modo a terem maior conhecimento e respeito com o planeta Terra, mudarem seus hábitos de consumo, quebrando paradigmas. Para isto, as novas tecnologias e sistemas devem ser sustentáveis e as interações humanas, colaborativas.

Este artigo explora diferentes formas onde o Design atua em prol da biodiversidade e, por último, propõe uma nova alternativa: o aplicativo Save the Bio. Este age por meio da educação e conscientização ambiental do usuário, disponibilizando informações e mostrando como é possível participar de uma causa em prol da biodiversidade de maneira rápida, simplificada e colaborativa.

O controle da perda da biodiversidade ainda é um grande desafio para a nossa sociedade e, se não mudarmos nossas atitudes, provavelmente tornar-se-á um problema com consequências cada vez maiores para as gerações futuras. Devemos cuidar da natureza e protegê-la, afinal, fazemos parte dela.

\section{REFERÊNCIAS}

ABREU, K. A. A importância social e econômica da biodiversidade. Revista Jurídica da Faculdade 2 de Julho, v. 01, p. 01, 2011.

ADG BRASIL. O valor do design: guia ADG Brasil de prática profissional do designer gráfico. São Paulo: Senac, 2003.

BOSTMAN, Rachel; ROGERS, Roo. O que é meu é seu: Como o consumo colaborativo vai mudar o nosso mundo. São Paulo: Bookman, 2011.

CAIXETA, R. A arte de informar. ABI, 2005. Disponível em:

<http://www.abi.org.br/paginaindividual.asp?id=556>. Acesso em 30 jan. 2015.

CANALTECH. Smartphones e tablets ultrapassam PCs em consumo de mídia. Canaltech Corporate, 2014. Disponível em: <http://goo.gl/c5rvDM>. Acesso em: 10 jul. 2015.

ESTADÃO. Brasil está à beira da maior extinção de espécies da história. O Estado de São Paulo, 2014. Disponível em: <http://goo.gl//WwePr>. Acesso em: 10 jul. 2015.

HYPENESS. 30 anúncios de animais que vão fazer você repensar seu estilo de vida. Hypeness, 2014a. Disponível em: <http://www.hypeness.com.br/2014/07/30-anuncios-de-animais-que-vao-fazer-vocerepensar-seu-estilo-de-vida>. Acesso em: 16 jul. 2015.

HYPENESS. Como uma simples imagem vai te convencer a não ter mais medo de tubarão. Hypeness, 2014b. Disponível em: <http://www.hypeness.com.br/2014/03/como-uma-simples-imagem-vai-teconvencer-a-nao-ter-mais-medo-de-tubarao >. Acesso em: 16 jul. 2015.

IDG NOW! Aplicativo que ajuda na vigilância da biodiversidade chega à Google Play. IDG Now!, 2014. Disponível em: <http://goo.gl/bk7gdQ>. Acesso em: 16 jul. 2015.

LEBOW, V. Price Competition in 1955. Journal of Retailing, 1955 . Disponível em: < http://www.gcafh.org/edlab/Lebow.pdf>. Acesso em: 16 jul. 2015.

LEONARD, Annie. The Story of Stuff - A história das coisas. EUA: Free Range Studios, 2007.

MINISTÉRIO DO MEIO AMBIENTE. Convenção sobre Diversidade Biológica - CDB. Brasília, 2000.

MOURA, Mônica, et al. Faces do Design. São Paulo: Rosari, 2003.

NUNES, M; SPITZCOVSKY, D. Biodiversidade nas regiões tropicais cai $\mathbf{6 0 \%}$ em $\mathbf{4 0}$ anos. Planeta Sustentável, 2010. Disponível em: <http://planetasustentavel.abril.com.br/noticia/ambiente/planeta-vivo-2010-wwfperda-biodiversidade-603803.shtml >. Acesso em: 20 mai. 2015.

PASCHOAL, F. Map of life: o aplicativo que mostra a biodiversidade que está próxima de você. National Geographic Brasil, 2015. Disponível em: <http://viajeaqui.abril.com.br/nationalgeographic/blog/curiosidade-animal/map-of-life-mol-o-aplicativo-que-mostra-a-biodiversidade-que-estaproxima-de-voce>. Acesso em: 16 jul. 2015.

ROGERS, Y. et al. Design de interação: além da interação humano computador. 3ed. Porto Alegre: Bookman, 2013. 585p. 
SANTOS, B. F. Homem acelera em mil vezes a extinção da biodiversidade. O Estado de São Paulo, 2014. Disponível em: <http://sustentabilidade.estadao.com.br/noticias/geral,homem-acelera-em-mil-vezes-aextincao-da-biodiversidade,1173618>. Acesso em: 15 jun. 2015.

SCHNEIDER, Beat. Design - Uma Introdução SCHNEIDER O Design no Contexto Social, Cultural e Econômico. São Paulo: Blucher, 2010.

STOPSHARKFINNING.NET. Find out about shark finning and how you can help to end it. Stop Shark Finning, 2013. Disponível em: <http://www.stopsharkfinning.net/>. Acesso em: 21 mai. 2015.

WALTRICK, Rafael. Pesquisa mostra aumento do uso de smartphones e tablets por jovens brasileiros. Gazeta do Povo, 2014.2 Disponível em: <http://www.gazetadopovo.com.br/tecnologia/conteudo.phtml?id=1506069>. Acesso em: 30 jan. 2015.

WILSON, O. Wilson. Biodiversidade. Ed. Nova Fronteira, 1997.

WWF BRASIL. Benefícios e custos do uso da biodiversidade. WWF Brasil, 2015a. Disponível em: <http://www.wwf.org.br/natureza brasileira/especiais/biodiversidade/beneficios custos biodiversidade>. Acesso em: 16 jul. 2015.

WWF BRASIL. Como a perda da biodiversidade afeta a mim e as outras pessoas? WWF Brasil, 2015b. Disponível em: $<$ http://www.wwf.org.br/natureza brasileira/especiais/biodiversidade/consequencias perda biodiversida de>. Acesso em: 16 jul. 2015.

WWF BRASIL. 0 que é biodiversidade? WWF Brasil, 2015c. Disponível em: <http://www.wwf.org.br/natureza brasileira/especiais/biodiversidade/o que e biodiversidade>. Acesso em: 16 jul. 2015.

WWF BRASIL. Quais são os principais motivos para estarmos perdendo tanta biodiversidade? WWF Brasil, 2015d. Disponível em:

<http://www.wwf.org.br/natureza brasileira/especiais/biodiversidade/motivos perda biodiversidade>. Acesso em: 16 jul. 2015.

WWF BRASIL. Quantas espécies estamos perdendo? WWF Brasil, 2015e. Disponível em: $<$ http://www.wwf.org.br/natureza brasileira/especiais/biodiversidade/quantas especies estamos perden do $>$. Acesso em: 16 jul. 2015. 